\title{
Infant and Child Mortality Status of Bangladesh: A Study on Demographic and Health Survey
}

\author{
Amzad Hossain ${ }^{1}$, Samiul Islam ${ }^{2}$, Serajum Munira ${ }^{3}$, Sakiba Farzana ${ }^{4}$, Swati Sarker ${ }^{1}$, Razu Ahmed ${ }^{5}$, Mostafa \\ Kamal Sarker ${ }^{6} \&$ Aktaruzzaman $^{7}$ \\ ${ }^{1}$ Department of Sociology, Government Edward College, Pabna, Bangladesh \\ ${ }^{2}$ Department of Sociology \& Anthropology, Green University of Bangladesh \\ ${ }^{3}$ Department of English, Green University of Bangladesh \\ ${ }^{4}$ Department of Sociology, Green University of Bangladesh \\ ${ }^{5}$ Department of Political Science, Government Edward College, Pabna, Bangladesh \\ ${ }^{6}$ Department of Sociology, Govt. Azizul Haque College,Bogra, Bangladesh \\ ${ }^{7}$ Department of Sociology, Chilahati Government College, Nilphamari, Bangladesh \\ Correspondence: Md. Amzad Hossain, Lecturer, Department of Sociology, Government Edward College, Pabna, \\ Bangladesh.
}

Received: December 2, 2017

doi:10.20849/ajsss.v3i1.330
Accepted: January 29, $2018 \quad$ Online Published: March 6, 2018

URL: https://doi.org/10.20849/ajsss.v3i1.330

\begin{abstract}
The objective of the study is to review in order to gain a better understanding of current status and achievement of child health and infant mortality related MDG's status from 2000 to 2014 in Bangladesh. In this regard, the study intends to review and analyze the MDG achievements status of Bangladesh mainly published by UNDP and BDHS. Building on the United Nations (UN) global conference of the 1990s, the United Nations Millennium Declaration 2000 marked a strong commitment which was adopted by 147 Heads of states, were what have become known as the eight Millennium Development Goals (UNDP, 2014). The overall proportion of birth attended by skilled health personnel increased by more than eight folds in the last two decades, from 5.0\% in 1991 to $43.5 \%$ in 2012-2013 (MDG Report 2014). In this circumstance, the committed target for Bangladesh is to reduce to 143 by 2015 . On the contrary, many national and international reports projected that in case of under-five year mortality, Bangladesh can be able to reach at 54 deaths per thousand live-births while the target is to reduce to 48 by 2015 . Bangladesh has made considerable progress in child survival rate as the mortality has declined rapidly over the last 10-12 years. The successful programs for immunization, control of diarrheal disease and vitamin-A supplementation are considered to be the most significant contributors to the decline in child and infant deaths. MDG report 2014 says that despite these progresses, there still remain challenges. While the mortality rates have declined substantially, inequalities in terms of access and utilization of health services among the populations still need to be addressed. To improve the MDG-5, some aspects such as unhealthy environment's impact on childhood diseases, poor uses of maternal healthcare services, different types of injury risks, high malnutrition and various technical, non-technical and administrative loopholes can be under highly considered. Greater efforts are particularly required in populous countries with mortality. In addition to medical and nutritional factors, improvement in other areas- notably education, access to safe water and adequate sanitation, adequate food, child protection and women's empowerment will also improve prospects for child survival and development. This paper also suggests that achievement in child mortality is positive but accomplishment of immunization is very much demanding. In conclusion, the health related MDGs are closely interrelated and require a joint and comprehensive approach. Although some progress has been made, it is uneven and there are much more remains to be done.
\end{abstract}

Keywords: achievements, child mortality, infant mortality, maternal mortality, Millennium Development Goals (MDG)

\section{Materials and Methods}

The study has been conducted mostly on the basis of BDHS, UNDP and others previous reports published at national and internal levels related to maternal health and child mortality issues in the context of Bangladesh. It is mentionable that, apart from the local perspective, the study also focuses on various reports conducted by the 
different international organizations or by individual researchers in recent times from global perspectives. The Objectives of the paper mainly emphasize on the previous child health mortality status and the challenges Bangladesh faced to reach the millennium development goals by 2015. However, the paper also shows a probable way out for Bangladesh to overcome the challenges and then reach the target of SDG related to child mortality.

\section{Child Mortality Perspective in Bangladesh}

UNICEF-supported national study in 2004 revealed that the leading cause of death among children aged 1 to 4 years is drowning, followed by pneumonia, malnutrition, and diarrhea. Some 22 per cent of infants are born with low birth weight, 43 per cent of under-5 children are stunted and 48 per cent of under-5s are underweight. Only 10 per cent of children are birth registered. An estimated 4.4 million orphaned children have lost a mother, father or both parents. Infant mortality has decreased from 100 deaths to 52 deaths per 1000 live births from 1990 to 2006. The under-5 mortality rate fell from 149 to 69 between 1990 and 2006. Neonatal deaths account for two thirds of infant deaths and over one half of all under-5 deaths (Unicef, 2005). The report also states that Bangladesh is one of the few developing countries on track to meet some targets for the Millennium Development Goals (MDGs), particularly those relating to nutrition, universal primary education and reducing under-five mortality. Five of the eight MDGs relate directly to women and children and The MDGs were born from the Millennium Declaration. The second point of the Declaration calls on the world's leaders to recognize their duty to the vulnerable "and, in particular, to the children of the world, to whom the future belongs" (Unicef, 2005).

Antenatal care is an essential component of safe mother-hood. The Bangladesh Demographic and Health Survey (BDHS) 1994 and BMMS 2010 indicate steady increases in the past 15 years with regard to the occurrence of at least one antenatal visit. The proportion of women who received at least one instance of antenatal care (by any provider) has increased from $28 \%$ in the early 1990sto $71 \%$ in 2010.

The Unnayan Onneshan, a local research centre in Bangladesh prophesized that globally agreed all eight Millennium Development Goals (MDGs): eradicate extreme poverty and hunger, achieve universal primary education, promote gender equality and empower women, reduce child mortality rate, improve maternal health, combat HIV/AIDS, malaria, and other diseases, ensure environmental sustainability and develop a global partnership for development by 2015, are closely connected and all the targets might be achieved if the targets of the health related Millennium Development Goals are achieved. By reviewing literature related to health related Millennium Development Goals in Bangladesh issue this paper finds that progress made by Bangladesh on the MDGs, especially those related to health, has been extremely slow. With only five years left, it might be quite difficult to achieve the health related Millennium Development Goals as in most of cases the progress is not on track rather far away from the desired target (UnnayanOnneshan, 2010 ). The major causes of infant deaths are acute respiratory infections, neonatal and prenatal problems, diarrhea, pneumonia etc. Neonatal and prenatal causes amount one-half or two-thirds of under-five mortality or infant mortality (GoB and UN, 2005). According to the Bangladesh Demographic and Health Survey (BDHS) 2007, each year 1.2 lakh newborn babies died within 28 days. Neonatal deaths now substantially amount 57 percent to overall mortality of children aged less than five years (BDHS, 2007). So, neonatal and prenatal care for the mother is very important. Around four in ten women receive no antenatal care. In rural areas, about 90 percent natal practices occur at home; while in urban areas, little over one-fourth of this practice is done at health care center (BDHS, 2007). Only 24.4 percent of births are delivered by skilled health personnel (MICS, 2009). There is a strong association between under-five mortality and mother's education. Unnayan Onneshan projection reveals that the projected infant mortality rate might possibly reach to 43 deaths per thousand live births by 2015 , which is higher by 12 deaths per thousand live births against the target. In 2009, the rate was 45 per thousand live births must be reduced annually by at least four deaths per thousand between 1999 and 2015. Infant mortality rate in Bangladesh, like under-five mortality rate, has also decreased impressively from 1990 to 2009. The average annual reduction between 1991 and 2009 was 2.84 percent against a target of 2.76 percent (UnnayanOnneshan, 2010). 


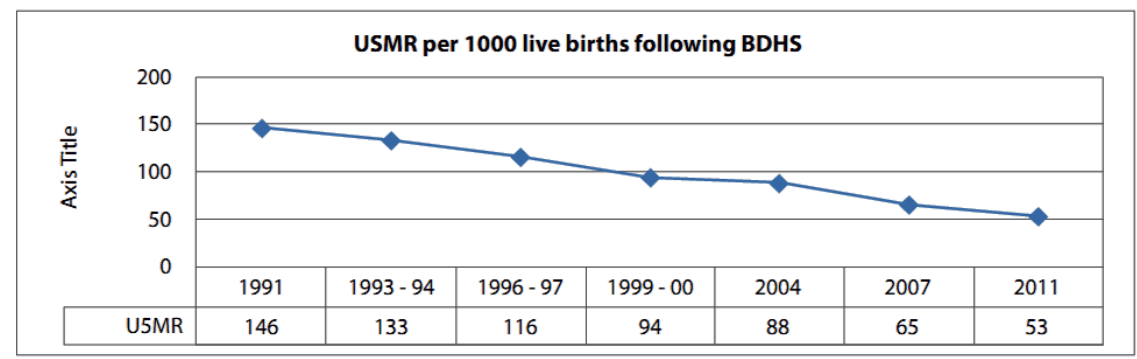

Source: BDHS, NIPORT, MOHFW (1993-94 to 2011)

Figure 1. Trends of Under-Five Mortality Rate 1991-2011 (following BDHS)

Under-5 mortality rate is the number of deaths among children under 5 years of age per 1,000 live births in a given year. The data from the Bangladesh Demographic and Health Survey (BDHS) 2011 show that there has been a remarkable decline (53 per 1,000 live births) in the under- five mortality rate since 1990. This means that one in nineteen children born in Bangladesh dies before reaching the fifth birthday. Between the 1989-1993 and 2007-2011 periods, more impressive (71 percent) decline was seen in post-neonatal mortality and 60 percent decline was evident in under- five mortality. The corresponding decline in neonatal mortality was only 38 percent. Comparison of mortality rates over the last four years shows that infant, child, and under-5 mortality declined by about 20 percent. As a consequence of this rapid rate of decline, Bangladesh is on track to achieve the MDG 4 target for under-5 mortality (48 per 1,000 live-births) by the year 2015 .

On the other hand, data provided by the Sample Vital Registration System (SVRS) 2011 show that the underfive mortality rate was 44 per 1,000 live births in 2011 as compared with 146 in 1991(BDHS 2011 ). This figure suggests that Bangladesh has already achieved the MDG target. In the case of rural areas, the under- five mortality rates for both sexes, male and female were 47, 50 and 43 respectively and, in the case of urban areas, these were 39, 37 and 41 respectively. The levels and trends in under- five mortality rate can be seen in above figure. At the national level the reduction was 70.9 percent for both sexes; while this was 70.8 percent for males and 71.1 percent for females, during 1990 to 2011. In the rural areas, under- five mortality rate for both sexes declined by 70.3 percent, the decline being 68.8 percent for males and 72.3 percent for females during 1990-2011. Over the same period, the reduction in the urban areas was 61 percent for both sexes, while it was 64.1 percent for males and 57.3 percent for females.

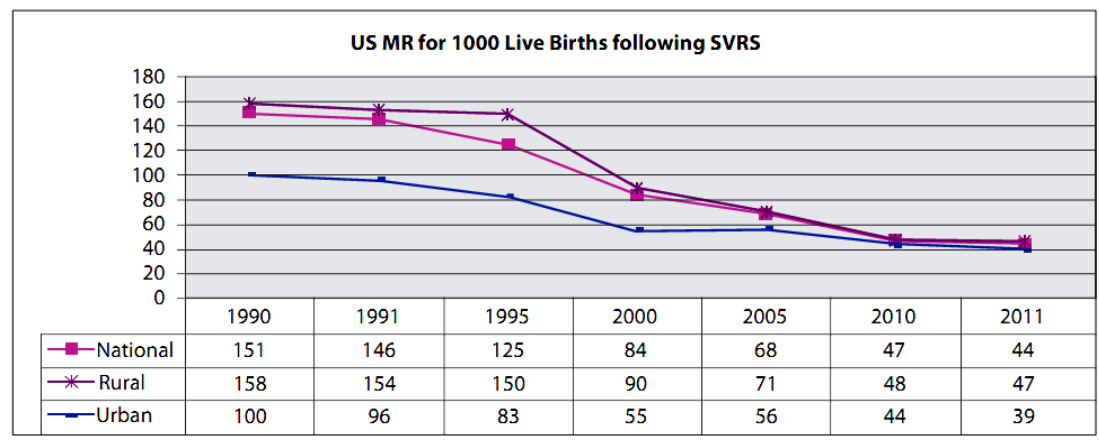

Source: SVRS, BBS, various years

Figure 2. Trends of Under-Five Mortality Rate, 1990-2011 (following SVRS)

Division level divergence of under-five mortality is also documented in the SVRS 2011. According to the survey, under- five mortality was the highest in Chittagong division (52) and lowest in Khulna division (41). In the case of males, it was the highest in Chittagong division (57) and lowest again in Khulna division (44). In case of females, it was the highest in Sylhetdivision (48) and lowest in Khulna division (40). In the rural areas, the highest under- five mortality was observed in Chittagong division (52) and the lowest in Khulna division (42) while, in the case of urban areas, again the highest was in Chittagong division (52) and the lowest in Khulna division (39). There exist many socioeconomic including behavioural and health related factors which underlie 
the regional differences in the under- five mortality rates across divisions. Also the rates differ for the 1-11 months and 12-59 months age groups as well as for the neonatal period. The surveys moreover show a sharp decline in under-five mortality with increase in wealth with the risk of dying by the age of five in the top quintile much lower than that for the bottom quintile (MDG, 2012).

\section{Challenges and Scopes to Meet MDG 4 and MDG-5 in Bangladesh}

Unicef suggested that Bangladesh has made significant progress in improving the health of its population, and is one of the few developing countries that is on track to achieve Millennium Development Goals (MDGs) 4 and 5. On top of the progress listed above, in 1990 the infant mortality rate was 100 deaths per 1000 live births and by 2006 it had declined to 52 deaths per 1000 live births. accelerate progress towards achievement of MDG 4, UNICEF is focusing its support in the following areas; i) improving community and household care seeking behaviors for sick children and neonates) working in selected districts to develop sustainable programs that will reduce drowning; especially among children aged 1 to 4, for whom it is the biggest single killer, and iii) the expanded programme on immunization (EPI) with emphasis on the poor performing districts and hard-to-reach areas. EPI annually vaccinates about 3 million children by their 1st birthday. These networks were channeled for the Measles Catch Up Campaign in 2005-2006, which saw 35 million children vaccinated against the preventable disease(Unicef-2005).

\section{MDG 4: Reduce child mortality}

MDG 5: Improve maternal health

Bangladesh Target:

Bangladesh Target:

To reduce deaths of children under 5 by two-thirds

by 2015 , so reduce the under-five mortality rate to 48To reduce the maternal mortality ratio by three quarters deaths per 1000 live births

between 1990 and 2015

\begin{tabular}{ll}
\hline Progress: & Progress: \\
\hline 1994: 133 & $1990: 570$ \\
\hline Current Status: 65 & Current Status: 320 \\
\hline 2015 target: 48 & 2015 target: 143 \\
\hline
\end{tabular}

Figure 3. Updated improvement in reducing child morality and maternal health

Source: (Unicef-2005)

A study on safe motherhood programs in Bangladesh found that women's low status in society, the poor quality of maternity care services, lack of trained providers, low up take of services by women and infrastructure all contribute to the high rate of child and maternal deaths. This is compounded by strong cultural and traditional ties that deter women from delivering at health centre's or with medically-trained attendants because their mothers have given birth "naturally" for generations. There is also little understanding about taking restore additional nutritious food during pregnancy. Moreover, the low status of women within the family means one in every two women will have her health care decided by her husband. Often her mother-in-law will be a key decision maker.

Another key factor in the high mortality rate is dealing with emergency obstetrics care. Despite the presence of a well-established service delivery infrastructure in Bangladesh and various measures taken so far, the utilization of emergency obstetric care (EmOC) services is still low. The Bangladesh Maternal Mortality Survey (BMMS) 2001 found there were delays in recognition of emergencies, and further delays in deciding what treatment should be sought. The BMMS found that one in five women could not decide whether to seek treatment within six hours of recognizing complications. There are then delays in travelling to treatment facilities, with the survey finding that traveltime was more than one hour in about one fifth of the cases (BMMS, 2001).

There are often delays in actually receiving the treatment and the costs involved are yet another deterrent for many people in a country where 36 percent of the population live on less than US\$1 a day (SOWC, 2007). Violence against women is another problem in curbing maternal mortality, with 14 percent of the deaths of pregnant women associated with injury and violence. Few women attend hospital after violence, or even for a checkup, because of the patriarchal social structure.

The Study opines that important concern in the health sector is maternal nutrition, as measures indicate around $50 \%$ of Bangladeshi women suffer from chronic energy deficiency. Low birth weight incidence is estimated at 
$45 \%$, and micronutrient deficiencies are common. Over $43 \%$ of pregnant women are iodine deficient and more than $2.7 \%$ develop night blindness during pregnancy (Bangladesh Ministry of Health and Family Welfare, 2000).

\begin{tabular}{ll}
\hline Country & Progress made for MDGs \\
\hline Bangladesh & MDG4 \\
\hline Nepal & MDG5 \\
\hline Cambodia & MDG6 \\
\hline Sierra Leone & MDG6 \\
\hline Liberia & MDG3 \\
\hline Rwanda & MDG4 \& 5
\end{tabular}

Figure 4. List of countries which received UN MDG Awards in 2010

Source- MDG 2013

The MDG report 2013 said that six countries including Bangladesh received the UN Millennium Development Goal (MDG) Awards for their significant achievements towards attaining the goal. Three of these countries are from Asia and three from Africa (MDG 2103, Where Bangladesh Stands?)When only 5 years are ahead to reach the dateline of year 2015 for meeting the targets of MDGs, assessment is ongoing throughout the world to find the answer whether or not the countries crossed sufficient road. The answer, in general, is no, although progress has been made in some areas. The same is true also for Bangladesh. A report has been published by the secretariat of the World Health Organization for the $63^{\text {rd }}$ World Health Assembly held in May 2010 (WHA document A63/7).

The report summarizes the current global status of the health-related MDGs. The report reveals that the global child mortality rate overall has shown declining trend; but uneven between countries; and the target may not be achieved in all countries. However, the interesting well-known fact is: about $40 \%$ of the under- 5 child deaths occur in the first month of the newborns' life and most in the first week. The rest $60 \%$ of under-five deaths occur due to malnutrition, HIV, vaccine preventable and other communicable diseases including pneumonia, diarrhea, and other causes. The report also said that the maternal health is the area which shows the poorest performance globally. In some countries of Africa the maternal mortality rate is about 900 per 100,000 live births, whereas the lowest figure in the world is 27 per 100,000 live births. It is evident that half of all maternal deaths occurred in the African Region and another third in the South-East Asia Region. Reports consistently show that most of the maternal deaths can be prevented if skilled care is ensured during pregnancy, child birth and postpartum period and emergency obstetric care is ensured. In both the African Region and South-East Asia Region, less than 50\% of women receive skilled care during childbirth. Maternal care during postpartum period also creates opportunity to look after newborn. Therefore, a comprehensive pregnancy care package can improve both maternal and child health situation.

The report narrated that Nepal has received a Millennium Development Goal (MDG) Award for significantly improving maternal health. Nepal was selected for the award from among 49 Least Developed Countries (LDC)s for the outstanding national leadership, commitment and progress towards achievement of the MDG goal related to improving maternal health. Cambodia has been presented with a Millennium Development Goals Award for its national leadership, commitment and progress towards achievement of Goal 6 - Combating HIV, malaria and other diseases. Cambodia has been honored within the 'Government' category of the annual Awards initiative, presented at a high-profile event in New York City.

Sierra Leone received the United Nations Millennium Development Goal (MDG) Award in recognition of President Ernest Koroma's remarkable leadership commitment and progress towards achieving the MDG6.Liberia has been named as the winner of this year's prestigious Millennium Development Goal Three (MDG 3) award for outstanding leadership, commitment and progress toward the achievement of the MDG-3 through the promotion of gender equality and women's empowerment across the country (MDG 2103, Where Bangladesh Stands?).

In the recent World Development Report (WDR, 2014), the World Bank specially focused on the issues of risk management as a means of enhancing MDG within the stipulated time. The following figure shows the WB's latest approach developed by the WDR team titled as 'A holistic approach to managing risks': 


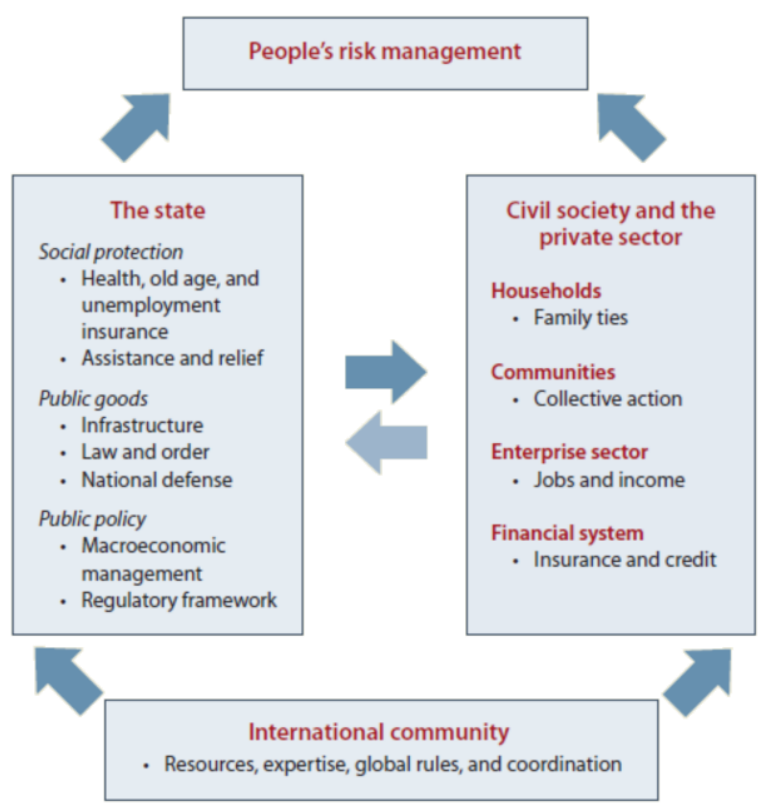

Figure 5. World Bank's conceptual framework for managing risks through social and economic systems Source: WDR, 2014

The framework identifies health issue as one of the prime one and suggests the management of risk through policy adoption focused on social protection based upon insurance. At the very beginning of the report, it introduces the concept of insurance as service that includes any instruments that transfer resources across people or over time, from good to bad states of nature (WDR 2014, Page:14). The success story of Turkey and Kyrgyz Republic influences the WDR team to adopt their experience as a prescribed model for the rest of the developing world. But the challenge for considering such prescription is that without contextualizing the social and economic reality of other countries, there may be negative outcomes as well. As a highly populous country like Bangladesh, addressing the health issue under the umbrella concept of insurance may not be realistic.

A conceptual framework of the millennium development goal of improving maternal health in Bangladesh suggested by Akhter and Wohab (2008) prescribes a kind of policy implementation guideline that can be presented in an abridges version as follows:

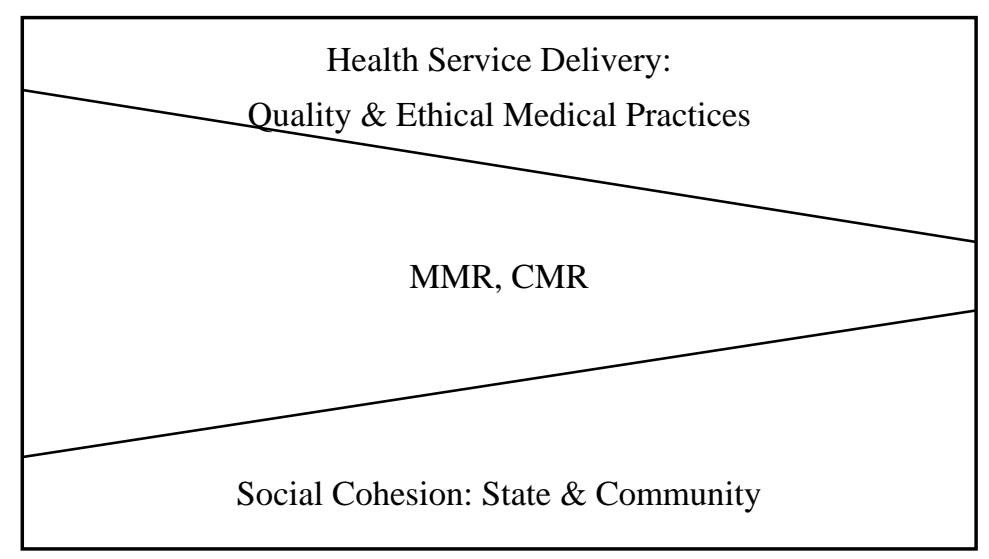

The framework suggests that quality health service delivery and social cohesion from state and community level has to be ensured at the same time. The more these two aspects of intervention will increase, the more MMR we shall be able to reduce.

In a recent research on Governance Challenges and the Way Out (2014), TIB addresses the challenges for 
ensuring health services in the Bangladesh. Despite the fact that there are numbers of studies on the quality of services and nature of irregularities in different institutions, there is a dearth of research that specifically covers governance related issues with particular emphasis on health services. As health is one of the priority sectors for TIB's activities, the present research has been taken. However, despite the above successes, governance challenges in this sector exist that hinder further achievements. According to TIB's National Household Survey (2012), 40.2\% of the recipients of health services from public institutions became victims of irregularities and corruption while receiving services. According to this survey the estimated amount of bribes at the national level in this sector was Taka 703 million. News reports on irregularities such as absenteeism of doctors, lack of quality of services, irregularities in getting bed and medicines, active presence of middlemen luring patients to private health facilities, financial corruption of the health professionals and hospital staff are regularly published in the print media (TIB.2000).

The following diagram shows the overall findings of the challenges for Bangladesh in the said research:
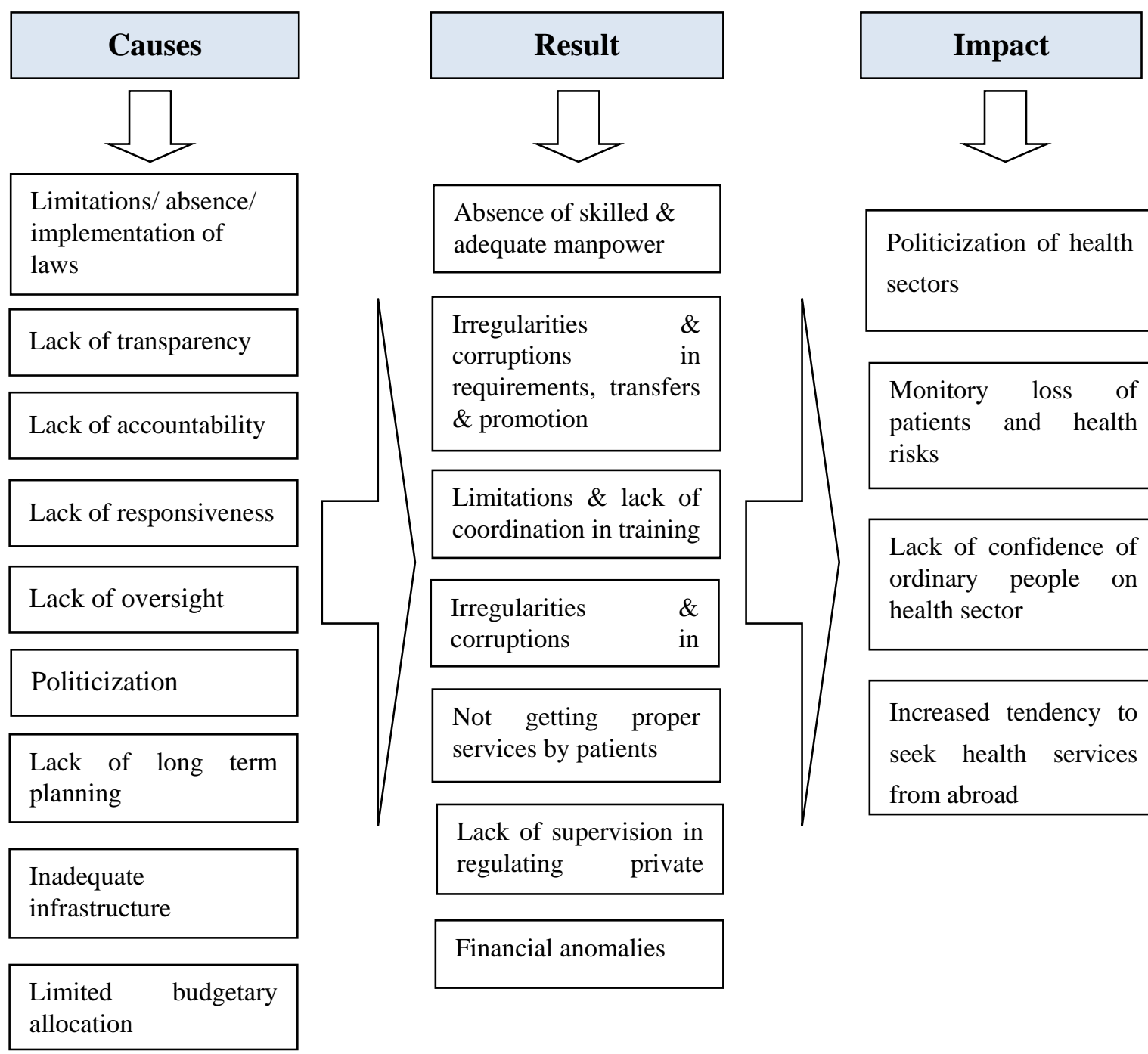

\begin{tabular}{|lr|}
\hline Irregularities & $\&$ \\
corruptions & in \\
requirements, & transfers \\
\& promotion & \\
\hline
\end{tabular}
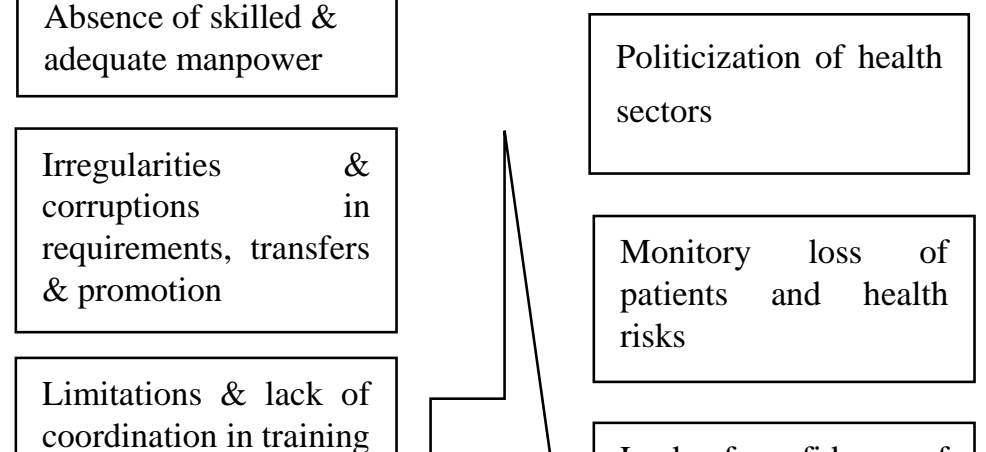

Monitory loss of
patients and health
risks
coordination in training

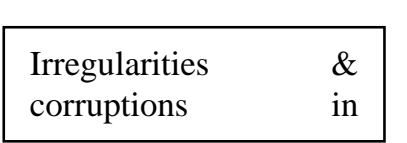

Lack of confidence of ordinary people on health sector

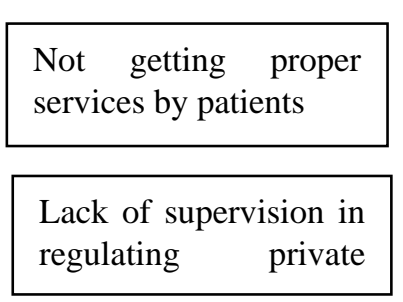

Increased tendency to seek health services from abroad

Financial anomalies

TIB also reported that sometimes, patients and their attendants experience corruption and irregularities during receiving services from health facilities. According to TIB's National Household Survey on Corruption 2012 $40.2 \%$ households experienced corruption while receiving health services. Moreover, various surveys conducted by TIB during 2011-2013 also revealed that some doctors do not attend their duties up to the official time at different levels of hospital particularly those in upazilas and districts; some patients do not get bed immediately after admission; some patients have to stay on floor up to a certain period, some patients are asked to go to doctor's private clinics and chambers and some patients expressed their unhappiness aboutthe quality of food they get from hospitals. Moreover, some patients have to make illegal payments for getting services from 
hospitals that include services like purchase of tickets, getting bed/cabin, use of trolley, doing different medical tests and investigations, pushing of injection and saline, dressing services and ambulance services, receiving services from ward boys and sweepers etc. Sometimes, patients are asked to go to doctor's preferred diagnostic clinics or centers for doing medical tests and investigations (TIB.2000).

The research findings of TIB advocates for the need of adopting an integrated policy that can remove the obstacles away from the path of our journey to meet the MDG4\&5. In the previous discussions of this article, the progress of Bangladesh in this regard creates the ground of being optimistic despite of having above stated challenges. The challenges rather create scopes for further growth in development in the overall health sector if we can address all the stakeholders and their functionality through in integrated and interactive approach. With such an intention, the following schematic framework has been suggested where recommendations from global and local expertise have been assembled in a sensible way and then emphasized on the management of local resources to boost up the achievements MMR and CMR status of the country as set by the MDG $4 \& 5$. The proposed schematic framework suggests three greater aspects of stakeholder at global and local level. Our previous development experience proves that not always the expertise from the global level is fit for the context of our local experience. But at the same time, there are so many expert areas where we need to share each other's learning and understanding adopting each other's ideas and other resources. For this, the triangle of GO, $\mathrm{NGO}$ /private sector and the international community must work together. We realize- prioritizing the local issues at international level may have some political or geo-political considerations. But, strong political leadership accompanied by grounded expert knowledge may overcome such situation. We have considered this issue in our schematic framework very seriously and our suggestion in this regard is a kind of ministerial integration of policy and operation of each other.

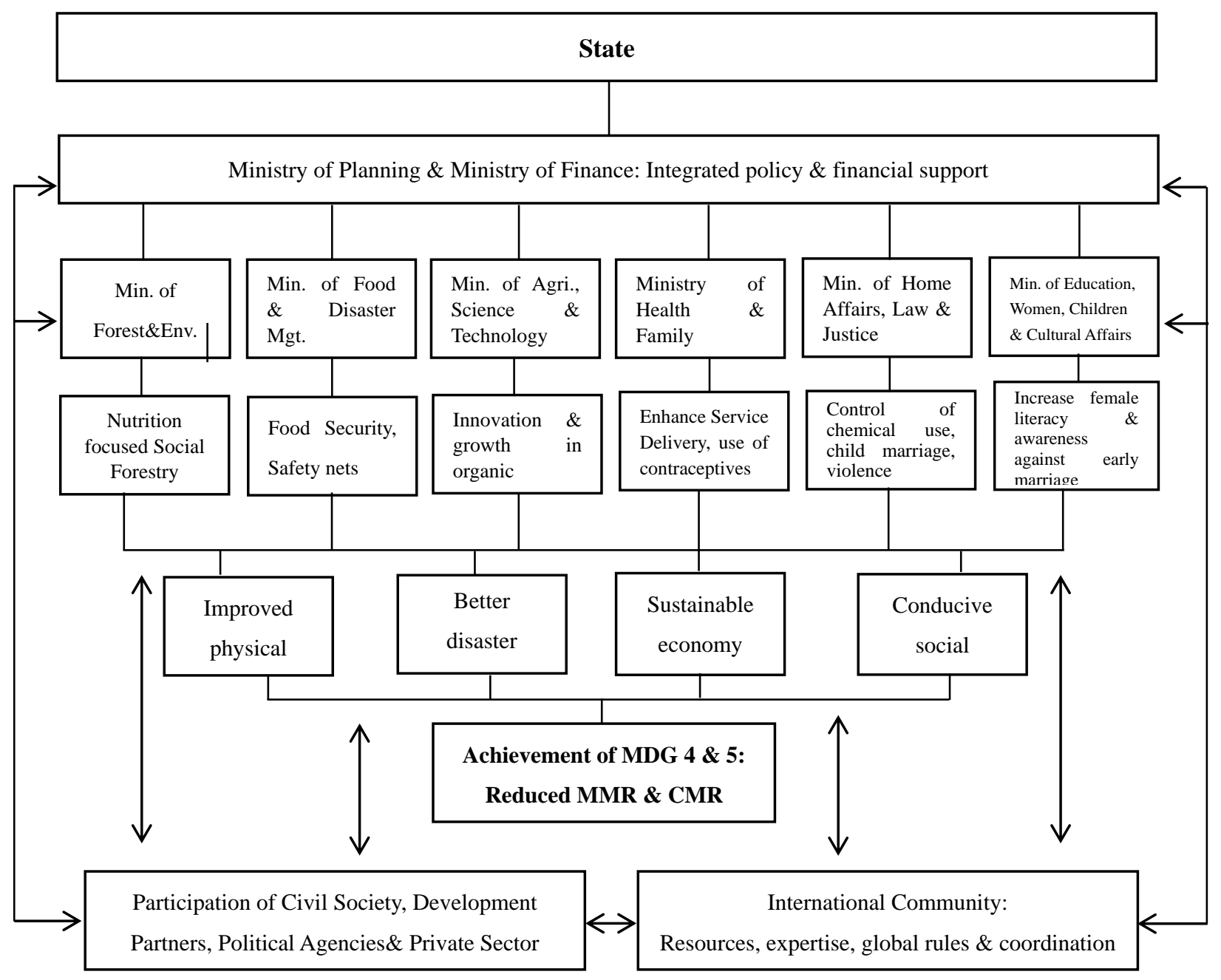

Figure 6. Integrated Policy Framework for Achieving MDG4 \& MDG5 (Recommended) 
For achieving MDG 4\&5, the framework refers to the ownership of health sector not only by the Ministry of Health \& Family Planning, but for all other ministries of the state. We perceive improving health status of the country or reducing MMR, CMR as a consequence of concerted efforts at all levels. This can be ensured through adopting a kind of public policy where the ownership of different public sectorsare cross linked. Such as, the Ministry of Forest \& Environment may adopt such a forestation policy where the health issue like nutrition will be addressed and thereafter will be resulted in availability ofvitamins through fruits through different social forestry programs.In same way, all the ministries are some way linked with the background of achieving MDG $4 \& 5$. So, if we fail to link those issues all together, a kind of progress may be achieved, but there is a question whether the condition will remain consistent the same in following age or not.We do not claim this schematic framework as a model taken for granted. Rather this is a kind of hybridization of different models already discussed in this article and then reflects on utilizing local recourses to manipulate our health related MDGs. Experts at different level may think critically about this and we are quite optimistic for further development of our developed idea.

\section{Conclusion}

The Transparency International Bangladesh (TIB) said that there are significant efforts and laudable achievements of the government in the development of the health sector. However, the achievements could have been higher if there were less limitations, irregularities and corruption. It is observed that there are lacks of long-term planning in terms of human resource management (recruitment, transfer and promotion), procurement management, control and supervision, and ensuring transparency and accountability. The monitoring and supervising system for public and private healthcare institutions is not strong. Moreover, the institutionalization of corruption in this sector particularly with regard to administrative and service-providing aspects is observed. (TIB.2000). Prof Shams El Arifeenet al (2014) pointed that the MMR fell from 322 deaths per 100000 livebirths (95\% CI 253-391) in 1998-2001 to 194 deaths per 100000 live-births (149-238) in 2007-10, an annual rate of decrease of $5.6 \%$. This decrease rate is slightly higher than that required $(5.5 \%)$ to achieve the MDG target between 1990 and 2015. The key contribution to this decrease was a drop in mortality risk mainly due to improved access to and use of health facilities. Additionally, a number of favourable changes occurred during this period: fertility decreased and the proportion of births associated with high risk to the mother fell; income per head increased sharply and the poverty rate fell; and the education levels of women of reproductive age improved substantially. We estimate that $52 \%$ of maternal deaths that would have occurred in 2010 in view of 2001 rates were averted because of decreases in fertility and risk of maternal death (Shams El Arifeen et al .2014). However, following such evidences, this paper reviewed the present status of maternal mortality and child mortality regarding MDGs status and provided some recommendations for falling of child mortality and maternal mortality in Bangladesh. According to Unicef the maternal health survey said that considerable progress has been made in increasing the coverage of Emergency Obstetric centers (EmOC) services. More and more women are seeking, and receiving essential and emergency obstetric care during pregnancy, delivery and after delivery. About 192 facilities have been strengthened to give comprehensive EmOC (59 district hospitals and 132 upazila health complexes). This has tripled the number of facilities and met the need for EmOC in the past five years. The number of public facilities providing comprehensive EmOC services has increased more than seven-fold since 1994. From 30 centers in 1994 there were 212 comprehensive centers in 2006. The proportion of deliveries at EmOC centers have also increased. Compared to a baseline study in 1999, there was a $93 \%$ increase in deliveries at Emergency Obstetric centers in 2006 (Unicef, 2011).MDG report last stated that Bangladesh is on track in meeting the target of this goal measured in three different indicators like under-five mortality rate, infant mortality rate and immunization against measles. The successful programs for immunization, control of diarrhoeal diseases and Vitamin-A supplementation are considered to be the most significant contributors to the decline in child and infant deaths along with potential effect of overall economic and social development (MDG, 2013). Despite these improvements, there are challenges ahead. While the mortality rates have improved, major inequalities among the population segments still need to be addressed. Childhood injuries, especially drowning, have emerged as a considerable public health problem responsible for a full quarter of the deaths among children 1-4 years of age. According to Bangladesh Maternal Mortality Survey (BMMS), maternal mortality declined from 322 in 2001 to 194 in 2010, a 40 percent decline in nine years (BMMS, 2010). The average rate of decline from the base year has been about 3.3 percent per year, compared with the average annual rate of reduction of 3.0 percent required for achieving the MDG in 2015. The BMMS 2001 and 2010 show that overall mortality among women in the reproductive ages has consistently declined during these nine years (BMMS, 2001). The Multiple Indicator Cluster Survey (MICS) of BBS and UNICEF have found 43.5 percent of women age 15-49 years with a live birth in the last 2 years were attended by skilled health personnel in 2012-2013, which was only 24.4 percent in 2009. The government has framed the National 
Health Policy, 2011' with a view to revamping the health sector and the 'National Population Policy 2012' has also been finalized. Moreover, in order to strengthen primary healthcare facilities, the government has launched 12,217 community clinics to expand health services to the grassroots level. The innovative idea to use the Information and Communication Technology for progress of the health of women and children has already been acclaimed by the world. However, challenges remains in the area of access to reproductive health. But all individual efforts must come under the umbrella of integration and interactions not only in policy papers and also in its operational means. The recommended schematic framework through this paper may function as a key to implement in achieving MDG $4 \& 5$ in this respect.

\section{References}

Afsana, K., \& S. F. Rashid. (2000). Discoursing birthing care. Dhaka: The University Press Limited.

Afsana, K., \& S. F. Rashid. (2001). The challenges of meeting rural Bangladeshi women's needs in delivery care. Reproductive Health Matters, 9(18), 79-88.

Akter. S, \& Wohab, M.A. (2008) Millennium Development Goal of Improving Maternal Health in Bangladesh: A Review of Bangladesh.

Bangladesh Demographic and Health Survey, 2004

Bangladesh Demographic and Health Survey, 2007

Bangladesh Demographic and Health Survey, 2008

Bangladesh Demographic and Health Survey, 2010

Bangladesh Demographic and Health Survey, 2012

Bangladesh Demographic and Health Survey, 2014

Bangladesh Maternal Maternal Mortality Survey, 2001.

Bangladesh Maternal Maternal Mortality Survey, 2010.

Bangladesh Ministry of Health and Family Welfare, 2002.

Barkat-e-Khuda, \& J. F. Phillips (Eds.), Reproductive Health In Rural Bangladesh: Volume I. International Centre for Diarrhoeal Disease Research, Bangladesh (ICDDRB), Dhaka.

Goodburn, E., A. R. Gazi, \& M. Chowdhury. (1995). Beliefs and practices regarding delivery and postpartum maternal morbidity in rural Bangladesh. Studies in Family Planning: 26(1), 22-32.

Habib, M. A. (2000). Study on quality of ANC service provided by selected MCWCs. MPH

Hlady, W. G., \& V. A. Fauveau, et al. (1992/1993). Utilization of medically-trained birth attendants in rural Bangladesh. Asia-Pacific Journal of Public Health, 6(1), 18-24.

K.M.MustafijurRahman. (2010). Health Related Millennium Goals in Bangladesh: A reality Check

Millennium Development Goals, 2012.

Millennium Development Goals, Report Last, 2014.

Millennium Development Goals: Where Bangladesh Stands?, 2103.

National Institute of Population Research and Training (NIPORT) and Bangladesh Ministry of Health and Family Welfare (May 2000), Bangladesh Demographic and Health Survey 1996-97.

National Institute of Population Research and Training (NIPORT) and Bangladesh Ministry of Health and Family Welfare, 2001.

National Institute of Population Research and Training (NIPORT) and Bangladesh Ministry of Health and Family Welfare, 2013.

National Institute of Population Research and Training (NIPORT), Mitra and Associates, and Macro International Inc. (1994). Bangladesh Demographic and Health Survey 1993-1994. USA.

National Institute of Population Research and Training (NIPORT), Mitra and Associates, and ORC Macro International, Inc. (2000). Bangladesh Demographic and Health Survey 1999-2000. Preliminary Report (June 2000). USA.

National Institute of Population Research and Training (NIPORT), Mitra and Associates, and ORC Macro 2001. Bangladesh Demographic and Health Survey 1999-2000. NIPORT, Mitra and Associates, and ORC Macro, USA. 
National Institute of Population Research and Training (NIPORT), Ministry of Health and Family Welfare, ORC Macro, Calverton, Maryland, USA and Johns Hopkins.

Rahman, S. A. (2000). Utilization of Primary Health Care Services in Bangladesh: The Population and Provider Perspectives. Ph.D thesis, Faculty of Science, University of London - London School of Hygiene and Tropical Medicine.

Shams, E., L. Arefin, Kenneth Hill, Karar Zunaid, Kantan Zamil, Quamrun Nahar, \& Peter Streatfield. (2014). Maternal Mortality In Bangladesh: a Countdown to 2015 Country Case Study.

Syad, M. (2014). .Bangladesh Health Scenario. Retrieved from www http://syedmasudahmed.blogspot.com/

Transperency International Bangladesh (TIB). (2014). Governance Challenges in the Health Sector and the way out.

United Nation Fund for Population Activities, 2002.

United Nation Fund for Population Activities, 2011.

United Nations Children's Fund for Children, 2005.

United Nations Children's Fund, 2005.

United Nations Development program(Bangladesh Chapter), 2013.

United Nations Development program(Bangladesh Chapter), 2014.

United Nations Development program, 2005.

University, USA (March, 2002), Bangladesh Maternal Health Services and Maternal Mortality Survey 2001.

UnnayanOnneshan, 2010.

World Health Assembly (WHA), held in May. 2010.

\section{Copyrights}

Copyright for this article is retained by the author(s), with first publication rights granted to the journal.

This is an open-access article distributed under the terms and conditions of the Creative Commons Attribution license (http://creativecommons.org/licenses/by/4.0/). 